\title{
The End of an Era: Sixteen Years of the Adelaide Theological Library
}

by Wendy Davis

\section{Presented at the End of an Era dinner held $12^{\text {th }}$}

November, 2013 at the Glenelg Golf Club. The dinner

marks the departure of Catholic Theological College from

the Adelaide College of Divinity. Catholic Theological

College ceases to exist from 2014. Catholic postgraduate

students will continue their studies through the

Australian Catholic University, and most staff of CTC will become part of the ACU faculty.

I

$\mathrm{n}$ the mid 1990s, the development of a joint library was a prime consideration and motivation in the push to create a common campus for the Adelaide College of Divinity (ACD). The benefits of bringing together the libraries of the ACD member colleges (Parkin Wesley College, St Barnabas College and St Francis Xavier Seminary) were apparent to all, but especially to the librarians Wendy Davis and Val Canty. In fact, Val and I were dreaming about and planning for this very eventuality, before the Common Campus plan came into being.

At some stage during 1996, even before the Brooklyn Park site was chosen, the Rev'd Dr John Roffey and I had conversations with the Flinders University Librarian (Bill Cations) and Deputy Librarian (Kaye Baudinette) which led to agreements between Flinders University Library and ACD whereby Flinders University Library would provide technical support and backroom processing (acquisitions and cataloguing) for Adelaide Theological Library (ATL).

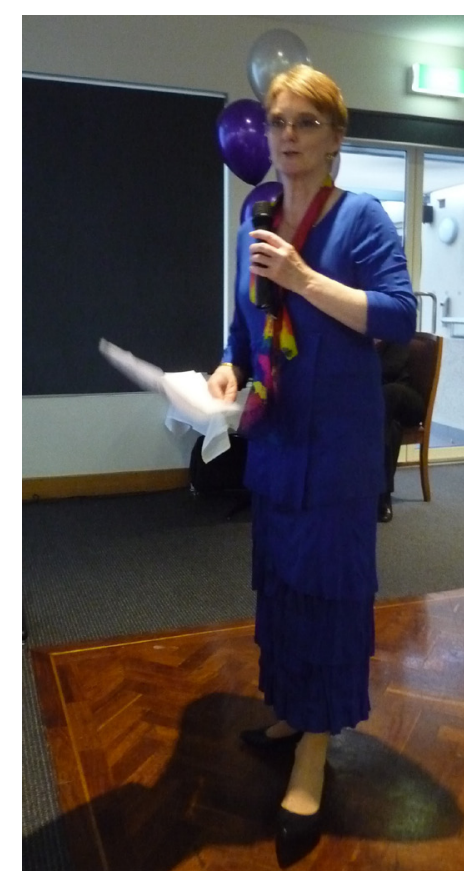


"These agreements considerably simplified the staffing and space requirements of the new library in that we would put in our orders and receive shelf ready books-meaning that we did not have to worry about the processes in between."
These agreements considerably simplified the staffing and space requirements of the new library in that we would put in our orders and receive shelf-ready books - meaning that we did not have to worry about the processes in between. It also gave us an instant online catalogue and all the technical support required to access it.

Once the site of the common campus was settled, the hard work began. Val and I had to prepare the libraries for the move-and it wasn't just a simple matter of selecting a removalist company, although that was a very important consideration!

Not only did we have to work out the layout of the new library, but we had to make sure that we had enough shelving to house the estimated 70,000 books from the three libraries and from St John's Halifax St (SSM) library. Using a special spreadsheet program from the University of SA libraries, we measured our collections so that each library could be shelved as it arrived at Brooklyn Park.

I have a few photos that were taken during the moving process that I thought may interest you.

The first library to be moved onsite was the SSM library. This arrived in early September 1997 and was shelved on the bookshelves left behind by the library of the Salesian College, the previous owner of the Brooklyn Park campus. The Reserve collections of the other libraries were also moved onsite ready for the beginning of term 4 when lectures began on the new campus.
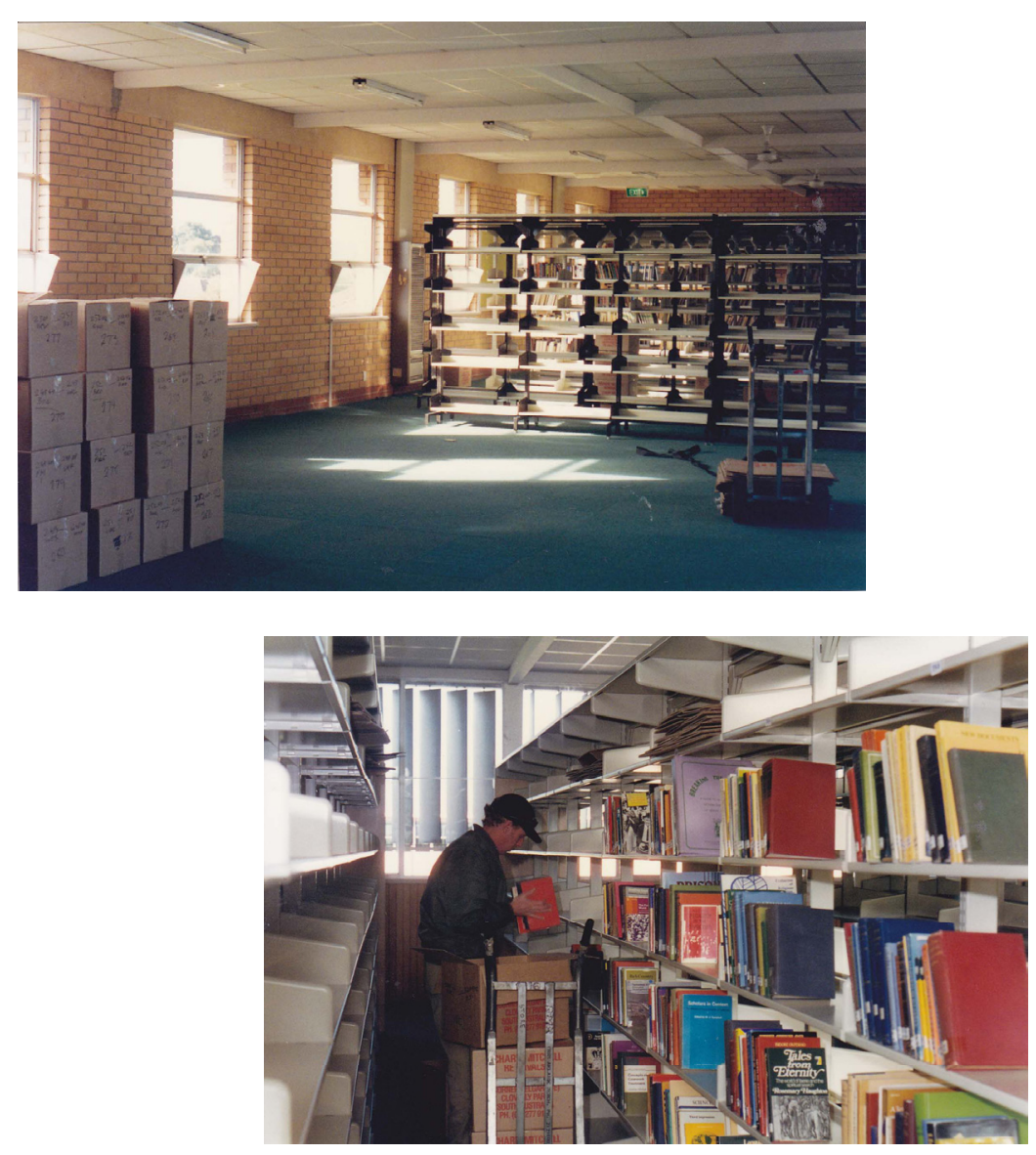
Beth Prior, the new Librarian, began work in mid-September. The other college libraries remained in operation during term 4 .

"Beth Prior, the new Librarian, began work in mid-September. The other college libraries remained in operation during term 4."

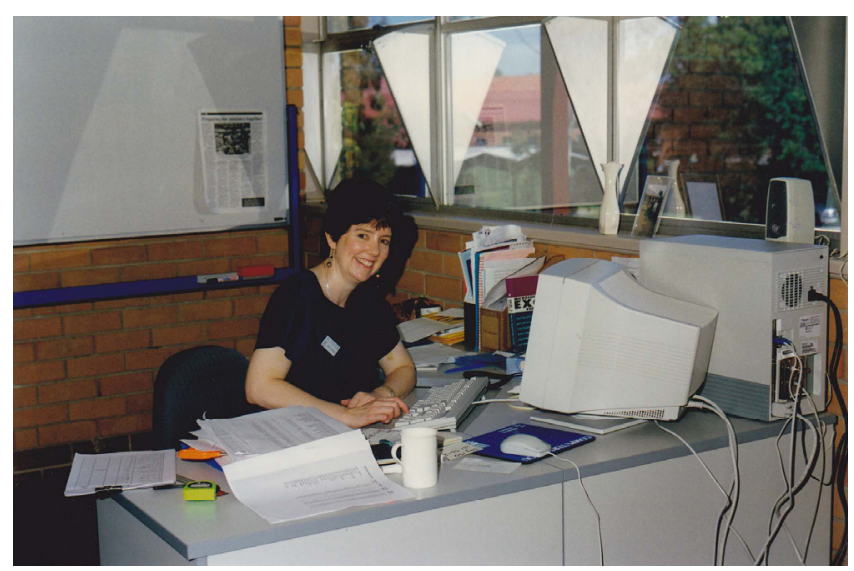

The next library to move onsite was the Gleeson Library, St Francis Xavier Seminary. This happened at the end of November after semester had finished. The first thing to do was to assemble all the shelving, and this is why SFX library was the first library to move. They had most of the shelving needed for the main stacks area.

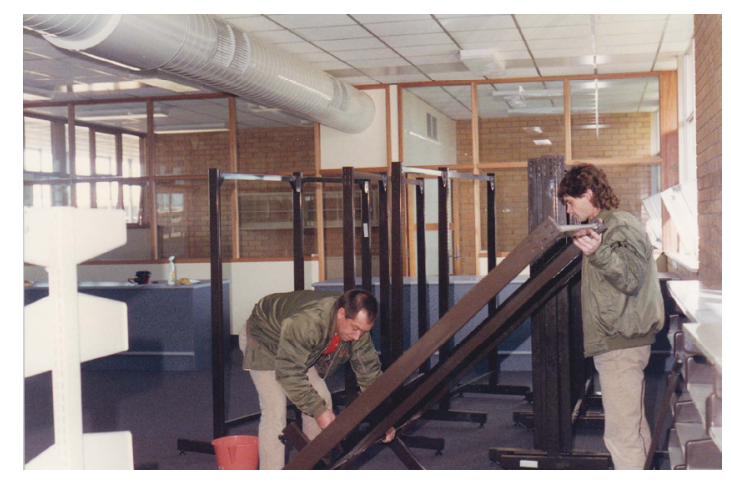

St Barnabas Library followed a couple of days later.

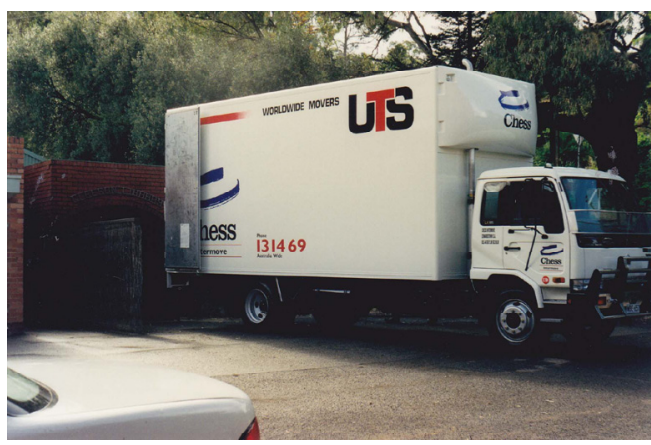


"Plan B had been

\section{to make what is}

now the Quiet

Study Room into

the Rare Book

Room, but again, the cupboards

were too big and it

was impossible to get them into the room down the new ramp."
... and finally Parkin Wesley library was moved onsite in the middle of December.
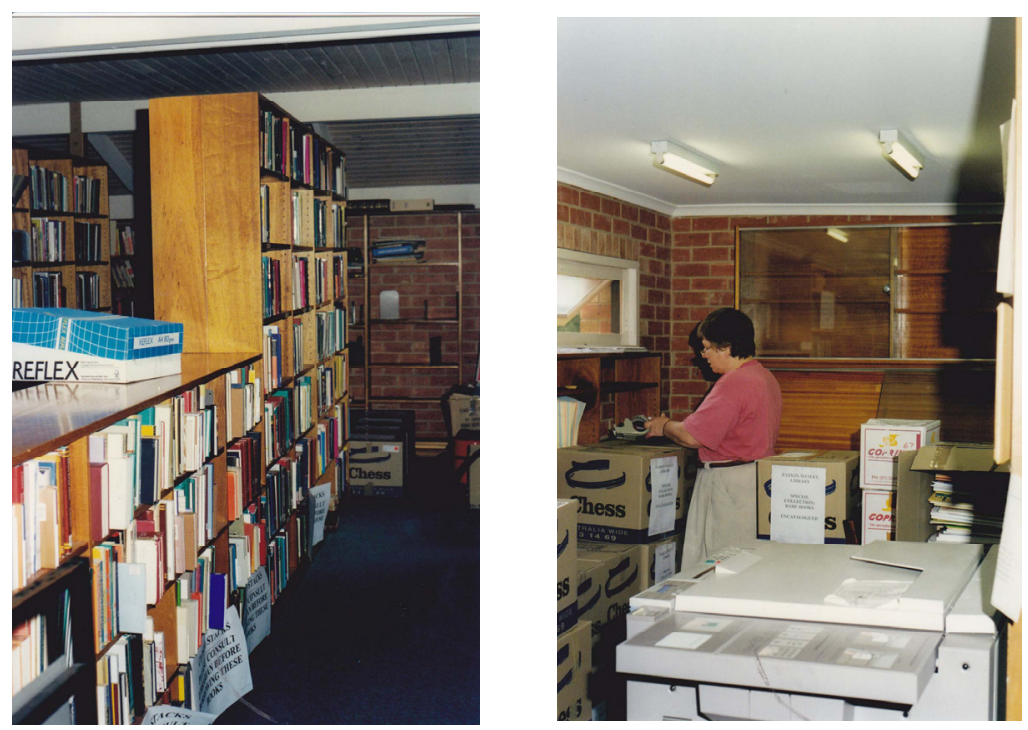

The Rare Books were about the only thing that didn't quite go according to plan- the beautiful wooden and glass cabinets were the problem. It was originally planned that they would go in the walk way between the circulation area and the main collection, but it was decided that they were too big. Plan B had been to make what is now the Quiet Study Room into the Rare Book Room, but again, the cupboards were too big and it was impossible to get them into the room down the new ramp. The corners were too tight.

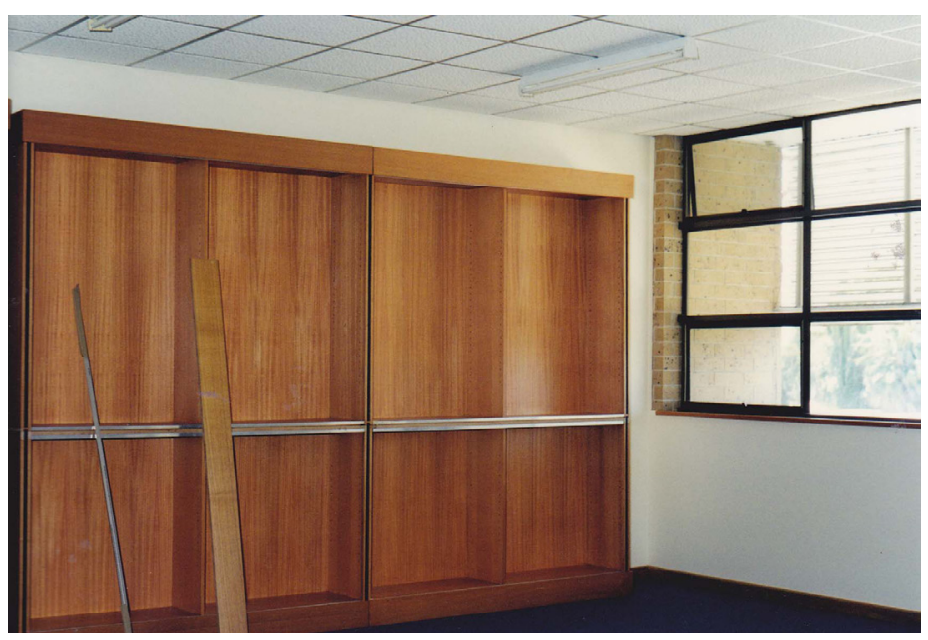

It was planned that they would be carried up the back stairs and into the Rare Book Room from there, but on moving day that was a drama too! We only just managed to get them through the newly constructed fire doors with a couple of millimetres to spare. 
"The good news is that the Adelaide Theological Library will continue into the future. We have been here for 16 years and we will continue to provide our services and facilities to the ACD and the wider theological community of all denominations."
.... and of course some students and lecturers continued to use the library despite the disruptions.

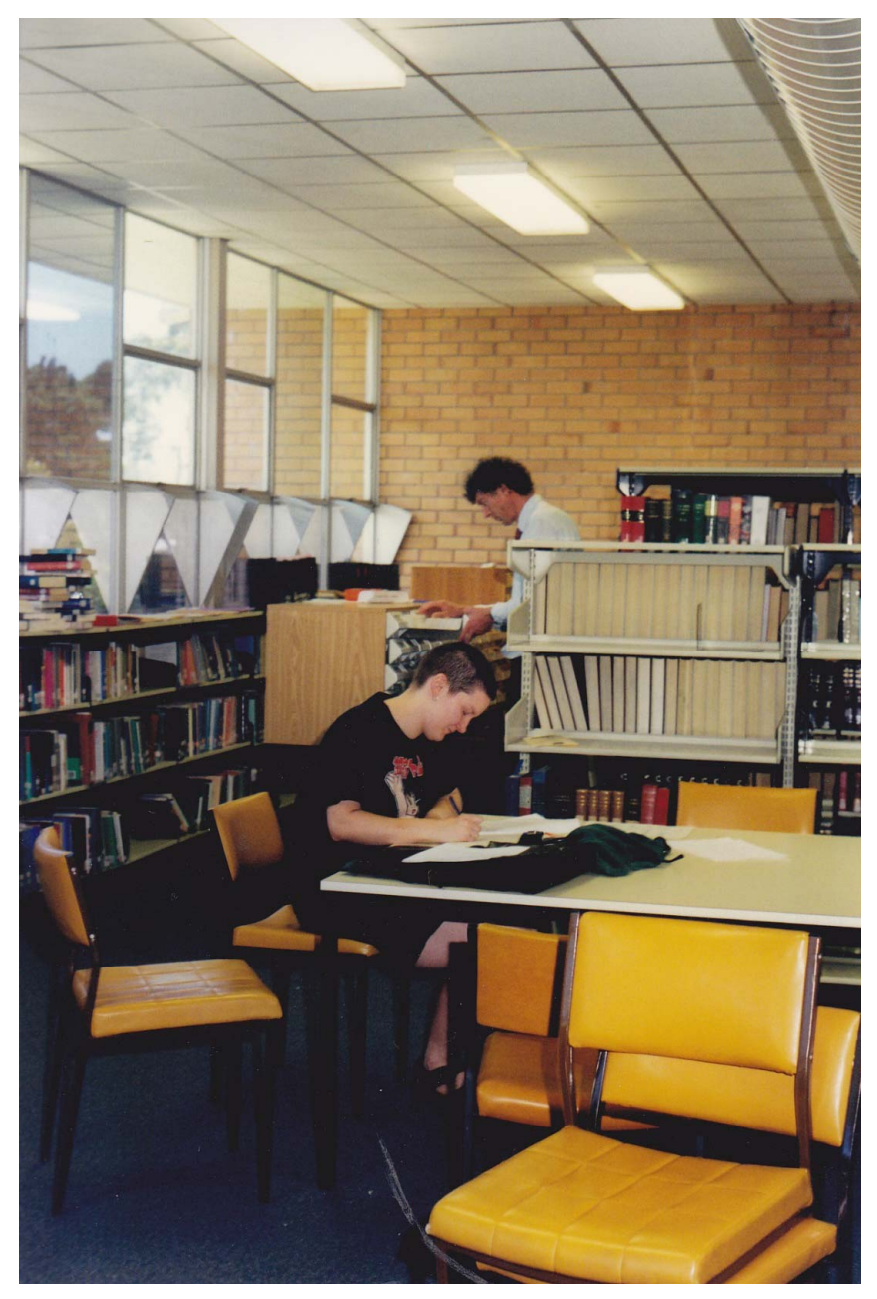

The good news is that the Adelaide Theological Library will continue into the future. We have been here for 16 years and we will continue to provide our services and facilities to the ACD and the wider theological community of all denominations. We will continue to develop our collection and provide a truly ecumenical meeting place.

Watch this space...

More of Wendy's images relating to the creation of a common campus library can be viewed by downloading the supplementary file (on the right-hand-side under Reading Tools). 